\title{
Bringing Open Data into Danish Schools and its Potential Impact on School Pupils
}

\author{
Mubashrah Saddiqa \\ mus@es.aau.dk \\ Department of Electronic Systems, \\ Aalborg University \\ Aalborg, Denmark
}

\author{
Lise Rasmussen \\ Department of Communication and \\ Psychology, Aalborg University \\ Copenhagen, Denmark \\ lisylykke@hum.aau.dk
}

\author{
Rikke Magnussen \\ Department of Communication and \\ Psychology, Aalborg University \\ Copenhagen, Denmark \\ rikkem@hum.aau.dk
}

\author{
Birger Larsen \\ Department of Communication and \\ Psychology, Aalborg University \\ Copenhagen, Denmark \\ birger@hum.aau.dk
}

\author{
Jens Myrup Pedersen \\ Department of Electronic Systems, \\ Aalborg University \\ Aalborg, Denmark \\ jens@es.aau.dk
}

\begin{abstract}
Private and public institutions are using open and public data to provide better services, which increases the impact of open data on daily life. With the advancement of technology, it becomes also important to equip our younger generation with the essential skills for future challenges. In order to bring up a generation equipped with 21st century skills, open data could facilitate educational processes at school level as an educational resource. Open data could acts as a key resource to enhance the understanding of data through critical thinking and ethical vision among the youth and school pupils. To bring open data into schools, it is important to know the teacher's perspective on open data literacy and its possible impact on pupils. As a research contribution, we answered these questions through a Danish public school teacher's survey where we interviewed 10 Danish public school teachers of grade 5-7th and analyzed their views about the impact of open data on pupils' learning development. After analyzing Copenhagen city's open data, we identified four open data educational themes that could facilitate different subjects, e.g. geography, mathematics, basic science and social science. The survey includes interviews, open discussions, questionnaires and an experiment with the grade 7 th pupils, where
\end{abstract}

Permission to make digital or hard copies of all or part of this work for personal or classroom use is granted without fee provided that copies are not made or distributed for profit or commercial advantage and that copies bear this notice and the full citation on the first page. Copyrights for components of this work owned by others than the author(s) must be honored. Abstracting with credit is permitted. To copy otherwise, or republish, to post on servers or to redistribute to lists, requires prior specific permission and/or a fee. Request permissions from permissions@acm.org. OpenSym '19, August 20-22, 2019, Skövde, Sweden

(C) 2019 Copyright held by the owner/author(s). Publication rights licensed to ACM.

ACM ISBN 978-1-4503-6319-8/19/08...\$15.00

https://doi.org/10.1145/3306446.3340821 we test the pupils' understanding with open data. The survey concluded that open data cannot only empower pupils to understand real facts about their local areas, improve civics awareness and develop digital and data skills, but also enable them to come up with the ideas to improve their communities.

\section{CCS CONCEPTS}

- Applied computing $\rightarrow$ Interactive learning environments; Collaborative learning.

\section{KEYWORDS}

open data, educational themes, impact, school pupils, educational resource.

ACM Reference Format:

Mubashrah Saddiqa, Lise Rasmussen, Rikke Magnussen, Birger Larsen, and Jens Myrup Pedersen. 2019. Bringing Open Data into Danish Schools and its Potential Impact on School Pupils. In The 15th International Symposium on Open Collaboration (OpenSym '19), August 20-22, 2019, Skövde, Sweden. ACM, New York, NY, USA, 10 pages. https://doi.org/10.1145/3306446.3340821

\section{INTRODUCTION}

Cities are an essential part of the future global economy. In 2008, according to a United Nations report [16], more people lived in urban areas than in the countryside for the first time in the history. It is also predicted that more than 75 percent of the global population will live in cities by 2050 . In order to fulfill the citizen's needs, cities are adopting new digital services, which capitalize on new technologies and applications - which in turn generates vast quantities of data. This big open data has the potential to further advance the quality of living in cities in myriad of ways [3,11]. To meet the challenges of urban population growth, cities around the world are seeking to reinvent themselves, aiming to be 
able to respond to their citizens needs [18] through efficient exploitation of big data.

The data generated as a result of citizen activity and the citizens themselves are an increasingly powerful resource [4]. Citizens are thus seen as active agents within the development process of a city. Generally, citizens are unaware of the data they are contributing and how they can take advantage of it. Open data gives the individual an opportunity to interact directly with data, but citizens need to possess the right skills and knowledge to benefit from this opportunity. Therefore, it is important to ensure that all citizens, especially the younger generations, are equipped with the skills essential to understand and make use of open data as they can bring a lot of value to the table when they are part of design and innovation processes [6].

In Denmark, more than 80 percent of the population lives in cities, and according to the 2018 Digital Economy and Society Index (DESI), Denmark is one of the most digital countries in Europe. Copenhagen, the capital of Denmark, is one of the top 20 smart cities in Europe according to a study carried out by EasyPark ${ }^{1}$. The city has a large collection of open data available to its citizens. To use this data and actively contribute to the improvement of digital services, open data literacy becomes imperatives for the citizen of Copenhagen. There are many examples how open data can serve the public, e.g. the findtoilet.dk ${ }^{2}$ service locate all the Danish public toilets, so that people with bladder challenges can now feel more comfortable when going out. Similarly mapumental ${ }^{3}$ in UK allows citizens more easily to find places to live, e.g. by estimating the duration of commuting to work and by having updated housing prices. As data is now a part of everyday life, it becomes the responsibility of the average citizen to have some level of data literacy and understanding in order to respond to public services in an effective way. Especially the young generation needs to learn how to work with data and develop digital skills. There is a growing demand to improve the digital skills and introduce interactive learning and teaching resources at the school level [22].

This research work is part of the Community Drive research project ${ }^{4}$. The project is a technical and humanistic research and development project that aims to establish comprehensive data-driven research and development collaborations between urban planners and the younger generation via a focus on the education of children and young adults in the community.

Community Drive deals with the city's many types of data and the collection and usefulness of relevant data regarding

\footnotetext{
${ }^{1}$ https://easyparkgroup.com/smart-cities-index/

${ }^{2} \mathrm{http}: / /$ www.findtoilet.dk/

${ }^{3}$ https://mapumental.com/

${ }^{4}$ https://www.strategi.aau.dk/Forskning/TvÃęrvidenskabelige+

forskningsprojekter/Community+Drive/
}

the city, the citizens, and the current data usage. The project focuses on how young people can be educated to foster participation in the development of the city using open data and sensor data, and how they can be empowered to conduct data collection on their own, and be taught to work with data documentation to represent their own districts using various types of data. The project has three phases. Figure 1 illustrates the different phases of the project.

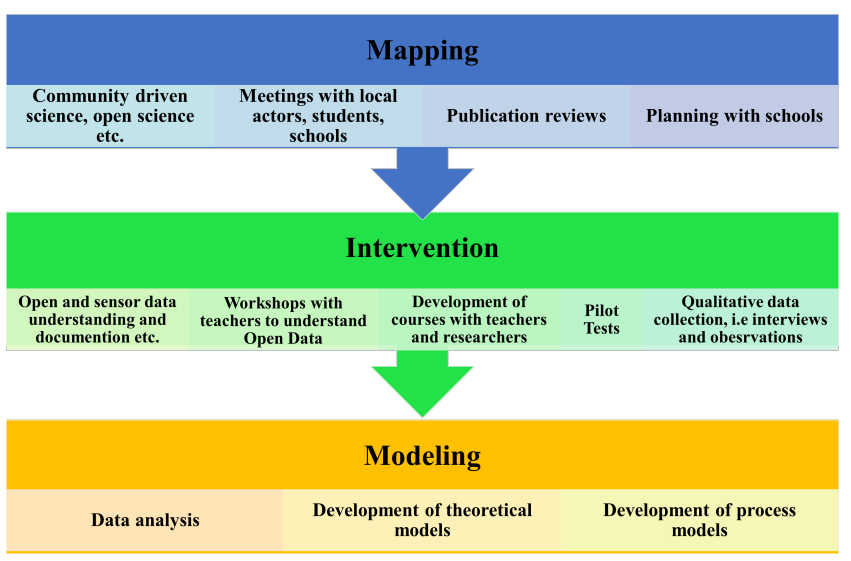

Figure 1: Different phases of Community Drive Project.

In the first phase of the project, key opportunities and issues for the development of re-designed educational models for the collaborated schools in close collaboration with the respective school teachers will be identified. The project participants are school teachers and pupils of 5-7th grades aged between 11-13 years. In the second phase, the education process will be developed and pupils will test their new digital and design based knowledge skills in the Southwestern part of Copenhagen, where the government has planned to launch the urban renewal processes to develop the Southwest neighborhoods of Copenhagen city. The final phase of the project compares data, results, and experiences from the two initial phases. Throughout the project, the pupils will not only develop their design-based knowledge, but also work with various data types, including open data. Figure 2 represents the different steps for school pupils to identify problems in the neighborhoods and create proposals for solutions using open data. School pupils will, in particular,

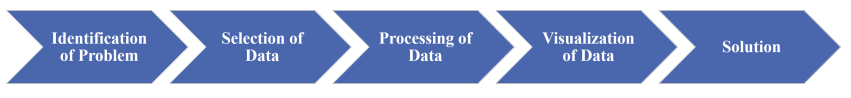

Figure 2: Steps for pupils to identify problems in the neighborhoods and to create proposals for solutions using open data. 
work with different types of the city's open data to understand different challenges and problems within their local areas. To familiarize pupils with the different data types of the city in an educational context, teachers play a central role. In this research work, we are intended to design experiments to communicate with teachers and investigate possible approaches to introduce the concept of open data as an educational resource. In the current paper, we present results from a qualitative interview study with Danish public school teachers and analyze their perspectives on the following research question:

"How can we best introduce open data in schools and what will be the potential impact on the pupils?"

The structure of the paper is as follows. The central concepts are discussed in Section 2, followed by an analysis of the characteristics of the Copenhagen's open data in Section 3. In Section 4, we discuss the method and key factors involved in the interview study. We present the key points from interviews for successful implementation of open data literacy and its impact on pupils in Section 5. We finally conclude the work in Section 6.

\section{BACKGROUND}

There is an ongoing emerging exploration in the technical areas of data analysis, machine learning and visualization within the scientific community [12]. However, a minor contribution has been made around the humanistic side specifically when dealing with data. What are the skills and competencies that individuals need in order to understand and solve problems with data? What new skills and abilities must humans acquire in order to design, interpret and analyze complex data and visualization? As the societies are becoming data dominated, it becomes a necessity to train the younger generation with essential data skills for the success of future plans, applications, business and smart cities.

Open data is creating new openings for people and societies, by improving not only efficiency and effectiveness of public services, creating jobs, and increasing government transparency [19], it can also act as a key, to develop digital and data literacy skills, enhance critical thinking, and civic awareness among students [1]. Open data are freely available data-sets that anyone can access, use and share without need of any licence. Open data is a potential resource of opportunities for public, for example, providing better and efficient public services (real time traffic applications, health and environmental services, etc.). However, the educational aspect of open data is not fully exploited, e.g. to support learning activities using open data as part of different subjects. For instance, open data could be used as an educational resource at school level to provide support in developing 21st century skills among younger students, especially digital and data skills, critical thinking, civic awareness, etc. using the real information of pupils' surroundings. For this, it is essential to associate the effect of open data at the ground level, i.e. schools and the pupils. In this research work, we are motivated to communicate with teachers and introduce the concept of open data as an educational resource at school level. Previous studies show that primary educational institutions are facing the challenge of not sufficiently educating children and young pupils for independent knowledge design and for finding solutions to complex societal challenges $[2,5]$. Previous work also indicates that the Danish elementary school is challenged by not sufficiently educating children and younger people to self-employed knowledge production and to develop solution for authentic complex problems [21].

The Organization for Economic Co-operation and Development (OECD) and a number of private research funds focused on new practices for open research and open innovation that encourages participation in the research and development process from non-academic partners. Such open 'quadruple helix' collaborators involve representatives from research, businesses, authorities and civil society and are considered in a number of publications as the key to greater and more responsible use of research knowledge [20]. Open research is first and foremost a research agenda that can lead to greater research impact in the society. This is emphasized at the same time by the strong growth in diversity and the amount of open data provided by public authorities [7]. Previously, highly specialized expertise was required to analyze big data, but now there are several tools that enable citizens and other laymen to independently work with big data analysis [13].

In order to enable children and younger people to interact and understand the concept of open data it is important to introduce open data literacy at school level. The main barrier to this interaction is the lack of problem-based education and engagement of school pupils in problem-based projects. They are not familiar with the open data and visualization technologies and its usage, and often open data may seem something for experts only. In order to enable pupils to make benefit from open data, data must be taught as part of different subjects. Thus, in order to know the pupils competencies to work with open data, its impact on pupils' learning behaviors and to figure out the possible challenges, it is crucial to know the teachers' perspective about open data literary at school level. In this research paper, we contribute with a teachers' survey and analyze the pupils' current data literacy skills and the possible impact of open data on pupils in their learning and everyday life. During the testing period of our project, we choose teachers and students from 5-7th grade as, in these grades students start working with basic concepts of data and its presentation, as part of mathematics and statistics. 
In the next section, we will briefly discuss the concept of open data with a brief analysis of the City of Copenhagen's open data to identify possible open data educational themes which could be used in different subjects as part of teaching activities.

\section{OPEN DATA}

According to Open Data Institution ${ }^{5}$, the data that is made available by organizations, businesses, and individuals for anyone to access, use and share is called Open Data. The Open data handbook ${ }^{6}$ defines open data [15] as the data and the content that can be freely used, modified and shared by anyone for any purpose. A city's open data continuously goes through many steps before it is transformed into valuable information. This includes the collection and the storage of data for further processing [17]. The key idea of analyzing open data is to extract the meaningful information from this data, which can be used for the betterment of community [14]. The data is examined and separated in different categories and formats to change it into a meaningful information. Moreover, data visualization is essential for presenting the information to the public in a structured and easy accessible form. There is ongoing research by different organizations and researchers to study open data [10]. Open data can be static or dynamic. Static data does not change much over time, for example, locations of the bus stops, train stations, and collective or historical data. Historical or collective data contains data points noted over a long period. These data sets will help in observing trends and correlations. Dynamic data, on the other hand, is the real-time data or data which is constantly changing, e.g. traffic density and the number of available parking places. Some of the main characteristics of open data are completeness, availability, usability, non-propriety, non-discriminatory, variety, updated, persistent and documentation as described in $[8,9]$. Data quality and data formats are also among the important features of open data.

In the following section, we will discuss the Copenhagen open data to explore different data themes that could benefits pupils as part of different teaching subjects.

\section{Copenhagen Open Data}

The City of Copenhagen is the capital of Denmark. The city is divided into ten main parts and then further divided administratively into smaller districts. The city is famous for having the world's best strategy for the collection and use of big data in order to provide the best digital services and to make the quality of life better ${ }^{7}$. The city has maintained a

\footnotetext{
${ }^{5}$ https://theodi.org/

${ }^{6}$ http://opendatahandbook.org/guide/en/what-is-open-data/

${ }^{7}$ https://www.europeandataportal.eu/sites/default/files/edp_analytical_ report_n4_-_open_data_in_cities_v1.0_final.pdf
}

very good quality of open data covering all aspects of quality, i.e. more recent, accurate and accessible data. As part of this research, we consider two main open data sources of Copenhagen city, Open Data $\mathrm{DK}^{8}$ and Open Data Copenhagen 9 . Both portals use the Comprehensive Knowledge Archive Network (CKAN) data platform for publishing the city's open data. CKAN is a web-based open source data catalog system, which is used to manage the storage and distribution of open data. It is mainly used by public organizations seeking to share their data with the public. Currently, there are 20 publishers and most of them are different departments of the City of Copenhagen. After analyzing the available open data of the city, we categorized the open data into ten general categories. Table 1 (on next page) presents the general categories with corresponding sub-domains. There are more than 290 available open data-sets. Figure 3 presents the distribution of open data-sets within general categories of the City of Copenhagen's data. The data-sets are of static, dy-

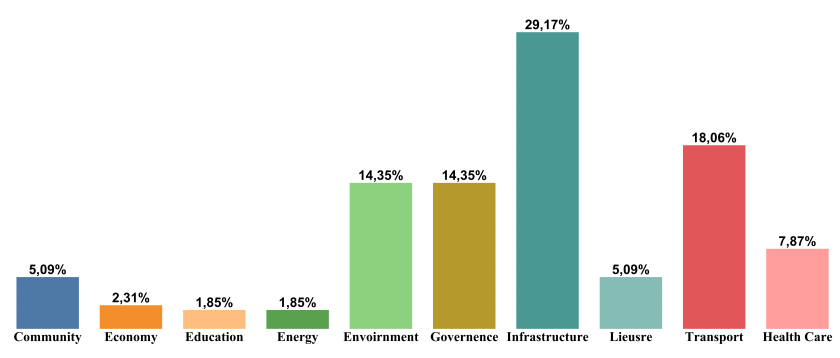

Figure 3: Open data-sets distribution among general themes of Copenhagen City

namic and geographical data types and are up-to-dated and timely processed. In the following, we describe some of the general themes identified in the City of Copenhagen open data. The description includes information about data types, data formats and number of data-sets with in the themes. This description will enables us to identify possible open data educational themes that could use as part of different teaching subjects.

Infrastructure: This category, for example, includes data-sets about the historical division of tax collection areas, currently used for statistical purposes. Data-sets about schools, swimming pools, play areas, bottle containers, toilets, cultural houses, libraries, and other similar locations are included. The data-sets are mostly static and are available in CSV, SHP, PDF, GeoJSON and DWG formats. There are around 63 datasets from different sources and most of them are up-to-dated.

\footnotetext{
${ }^{8}$ http://www.opendata.dk/

${ }^{9}$ https://data.kk.dk/
} 
Table 1: Copenhagen's Open Data General Categories

\begin{tabular}{ccl}
\hline No. & General Domain & Sub-domains \\
\hline 1 & Governance & Elections, Census, Transparency, Demography, etc. \\
2 & Environment & Pollution, Water Quality, Traffic, Climate, Nature, Noise, etc. \\
3 & Health and Care & Social Care, Care homes, Child Care, etc. \\
4 & Infrastructure & Roads, Buildings, Locations, Planning, etc. \\
5 & Transport & Transport, Parking, Public Transport, Pedestrian, Cyclist, etc. \\
6 & Community & Society, Housing, Employment, etc. \\
7 & Education & Schools, Kindergartens, etc. \\
8 & Energy & Solar Energy, Energy Consummation, Carbon Emission, etc. \\
9 & Culture and Sports & Entertainment, Tourism, Cultural Places, Recreational Activities, etc. \\
10 & Economy & Economy, Finance, etc. \\
\hline
\end{tabular}

Transport: This category contains data about transport, i.e. traffic, roads, cycle paths, bus stops, bus routes, parking areas, traffic signals and pedestrian. In total, there are 39 data-sets with in this theme - most of them collected through sensors. These data-sets are available in CSV, XLS, GeoJSON and SHP formats.

Governance: This section contains information about local plans, election, census, population, age, gender, income and details about pension, insurance, and socio-economic details. These data-sets are also static in type and most of them are in CSV format. There are 31 available data-sets.

Environment: This section contains information about climate, pollution, carbon level, noise level, traffic pollution and about nature and trees in the city. The data-sets includes both static and dynamic data and are available in CSV, GeoJSON, SHP, DWG and PDF formats. There are 31 data-sets.

Community: This category contains data-sets mainly about education, employment, unemployment and housing. The data-sets are static and are available in XLS, PDF and CSV formats and there are 11 data-sets.

Health and Care: This category contains data-sets social care, child care and about benefits distributed geographically, e.g. sickness, cash, job seeking and flexible job allowance. The data-sets are static and are in XLS and CSV formats. There are around 17 data-sets with this theme.

There are open data-sets covering other important categories, e.g. culture, art, youth, sports and entertainment, hospitals and other public sectors. The brief survey of Copenhagen city's open data will enable us to present different open data-sets which can be used at school level as part of different teaching subjects. For example, data-sets about geographical distribution of the city, traffic details, pollution and population could be used as real examples in geography, science and math's subjects.

\section{Open Data Themes Corresponding to Educational Domain}

We have carefully analyzed the main themes of Copenhagen's open data and produced 4 open data educational themes which can easily relate to specific educational domains, i.e. mathematics, science, geography and social science. These includes environmental data, statistical data, demographic data and geographical data. Figure 4 represents open data themes with corresponding sub-domains which can easily relate to specific educational domains.

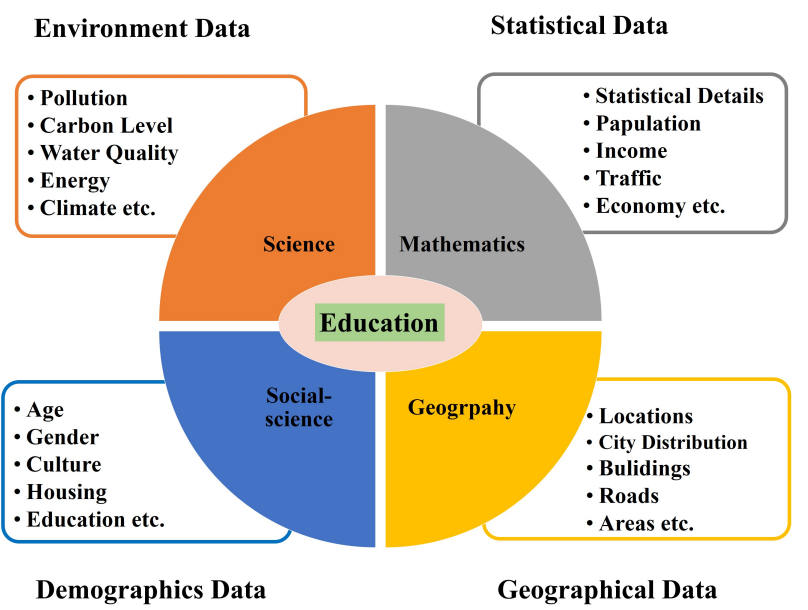

Figure 4: Educational open data themes corresponding to specific educational domains

For example, environmental data can be use to view the city's pollution level, carbon level and water quality at different parts of the city as part of physics and chemistry tasks. Statistical data could be used to compare different statistical details about population, age and income when teaching mathematics or statistics. Geographical data could be used to 
view the geographical distribution of the city, roads and locations, etc. as part of geography assignments. Demographics data could be used in social science tasks to view the details of citizen in a particular part of the area, their age, income, education and housing details, etc. We will use specific open data-sets from the educational themes, e.g. population, pollution, income, education level and traffic data-sets as examples during the interviews to understand the teachers' perspective about introducing open data as part of their teaching subjects and what would be the possible impact on pupils' learning abilities.

\section{METHOD}

In order to analyze the teachers' perspective about bringing open data into schools, its impact on pupils, and which competencies they need in order to collaborate with open data, we collected data through teacher's survey and observing open data activities with pupils. For survey and observation, 10 teachers from 6 different Danish public schools and 12 school pupils of 7 th grade aged 12-13 years, participated. We choose teachers from 5-7th grade as, in these grades pupils start developing basic concepts of data and its presentation as part of mathematics and statics. Table 2 shows an overall view of the participants. Teachers are identified according to their subjects, grade levels, experience and location of the schools and the details are as follows:

- Subjects: Mathematics, Science, Geography and Social Science

- Grades: 5-7th

- Experience: 3-15 years

- Age: 25 to 40 years, in order to get feedback from a range of perspectives, e.g. from young teachers to as well as senior teachers.

- Schools: Copenhagen public schools situated near the Southwestern part of the city where the future project will be carried out or other schools situated in similar deprived areas.

For survey, we interviewed public school teachers identified according to the criteria stated above. The structure of the interviews were both one-to-one and group interviews. Individual interviews were carried out with 8 teachers. Three teachers were interviewed as a group. The interviews were carried out in Danish language with teachers consent to record interviews using audio devices. The duration of interviews was 1.5 to 2 hours. In the beginning of the the interview, presentations of 10-15 minutes on open data with use cases were presented to teachers followed by open discussions. After the presentations the teachers were asked verbal and written questions in the form of online questionnaire. To investigate the research question in different aspects, we sub-divided the research question into three categories:
Skills and Competencies: We asked teachers about how often they work with data in their teaching tasks, which tools they already used to present data, which types of graph they commonly used, e.g. line, bar, pie charts etc., to investigate what abilities do pupils already have to work with data? What skills would be necessary? We also asked about different technologies already used in schools and which visualizations tool would be appropriate? How far pupils are familiar with data collection concepts?

Open Data Impact: What would be the benefits of open data in teaching? What would be the impact of open data on pupils' learning behavior? What are the teacher's views on using real local area examples in their teaching? What datasets would be interesting for pupils as part of the teaching subjects.

Challenges: We asked about different problems and challenges in relation to bringing open data into schools, and suggestion as to how these could be overcome.

To bring open data into schools, there are also some key factors that play an important part in using open data as an educational resource. During the survey, these factors are considered to know how teachers understand and could work with these factors. For example, how they can relate simple open data visualization with different subjects and for open data presentation, which visualizations tools and techniques teachers can use. Which types of visualizations are easily understandable by the pupils (line, bar, pie, maps, etc.), or how they can collect live data using sensors or other technologies to give hands in experience to younger students, e.g. physical data using trackers or room's environment using sensors.

The next section describes the key factors chosen for their potential role in developing open data literacy in schools. These key factors are considered in developing the questionnaire to get the best possible feedback from teachers.

\section{Key Factors}

The following key factors are discussed during the interviews with teachers to understand their perspective about open data education in schools. During the interviews, we explained these factors briefly to the teachers so that they were well aware of these topics and their use in real life.

Open Data visualizations: In order to explain which type of data-sets are available on the city website, we presented datasets with in educational themes discussed in Section 3, e.g. data about population, city division, and socio-economic data. These data-sets are big in size and are in different formats, e.g. GeoJSON and SHP and it was difficult for the teachers to understand these. We therefore transformed these data-sets 
Table 2: Overview of Survey's Participants

\begin{tabular}{ccccc}
\hline Participants & No. of Participants & Grades & Activity Type & Duration \\
\hline Teachers & 10 & 5-7th & Interviews, Questionnaire, Open Discussion & $1.5-2 \mathrm{hrs}$ \\
Pupils & 12 & 7th & Observation & $1-1.5 \mathrm{hrs}$ \\
\hline
\end{tabular}

into CSV and XLS formats and also split the bigger datasets into smaller data-sets containing the information about the local areas of respective schools. In this way it became easier for the teachers to understand the information. We then asked the teachers about their perspective on the use of open data-sets as part of science, math or geography subjects. Their feedback will be discussed in the next section.

Visualization Techniques: The data itself has little meaning without representation. The Danish public schools already used different tools for the representation of data. Some of them are:

$$
\begin{aligned}
& \text { - GeoGebra } \\
& \text { - Microsoft Excel } \\
& \text { - WordMat }
\end{aligned}
$$

In order to work with open data, it is important to use a software which is compatible with big data-sets, easy to access, user-friendly and provides free licensing for schools. We visualize open data-sets using different visualization software which provides free academic programs for teachers and pupils, e.g. Tableau, QlikView etc. Figure 5 is an example of open data-set visualization using Tableau. It represents the statistical details of Sydhavens district of Copenhagen city. We want to investigate the teachers' views about the complexity of the new tools in comparison with the tools they already used in their teaching. We also asked about the challenges in introducing new technology in the schools.

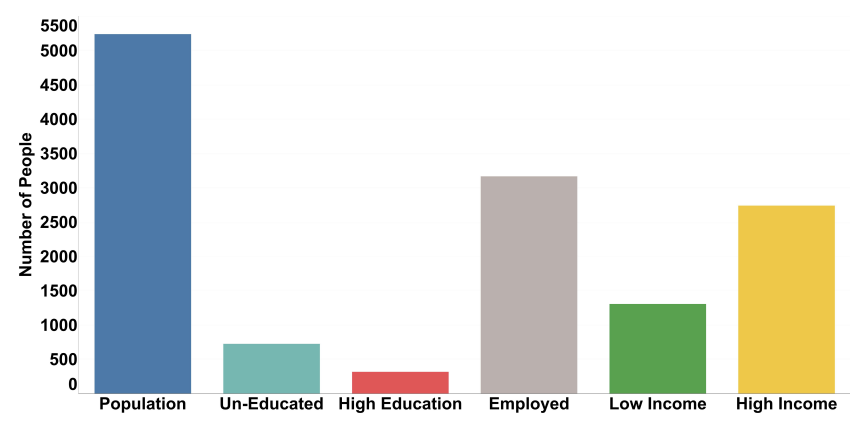

Figure 5: Statistical Details of Sydhavens district of Copenhagen Using Tableau

Sensors and sensor data: Sensors plays an important role in the collection of real-time data. Many data-sets from city website are generated from sensors, e.g. data about traffic, noise level, and light. As part of the Copenhagen Community Drive project, pupils are expected to use sensors for the collection of data in relation to understand and identify different problems of the local areas near the schools, e.g. lack of light, noise level or similar. We presented examples of environmental sensors to the school teachers shown in Figure 6. These sensors are used to measure air quality, temperature, humidity, and similar other parameters and are for indoor use. We also introduce outdoor sensors which can count the number of people passing by a specific path using wifi-devices as shown in Figure 6. We described different functions of sensors and how teachers can use these sensors to measure different parameters. We also showed them the graphs of generated data for different parameters such as humidity, temperature etc., to help them understand how they can work with sensor technology. We then asked the teachers about their views on pupils' interest in such technology, how useful it might be and how they might use sensors in their teaching plans.
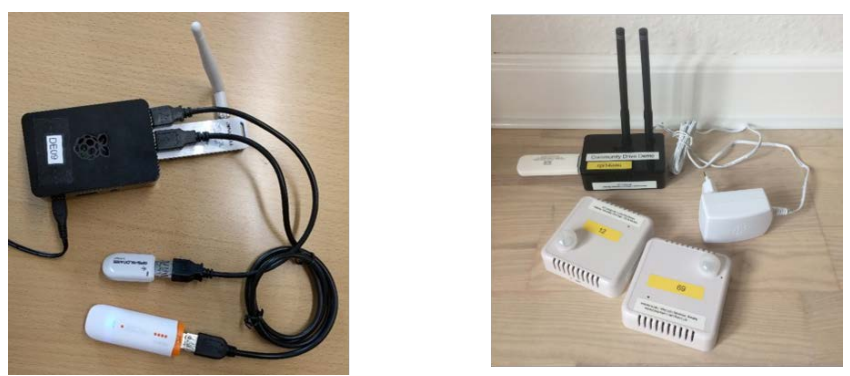

Figure 6: RuspberryPi and Environmental Sensors

Experienced data and its collection: The concept of experienced data is also one of the key points in the interview study. In Danish public schools, different data collection methods are already used. These vary from teacher to teacher and grade to grade. These include quantitative, qualitative and technology-based methods. We asked the teachers about different tasks where pupils collect data with their own experience as part of their studies.

We asked teachers about the research questions, key factors and pupils current skills in relation to work with open data and its presentation. The questionnaire consists of structured questions and open ended questions about open data, 
its use, its impact, required skills and competencies and potential challenges. Based on their feedback, key points are formulated which are discussed in the result section.

\section{Observation}

To investigate the best possible impact of open data in schools, we use the observation method with a group of 12 pupils of 7th grade aged around 12-13 years along with their respective science teacher. We use audio and video devices to observe the experiment with pupils' permission. The experiment was one and half hour long. The pupils were provided with information about pollution level near their school area using simple open data visualizations. The teacher first explain the pollution graph and afterwards the pupils were asked to discuss it with each other and explain what they understand or share any useful information from the graph. After the discussion, the pupils pointed out that at some periods of the day the pollution level is higher in the morning and afternoon timings, because this is the time when most of the pupils are dropped off and picked up by their parents. We asked pupils how the environment could be improved for the whole day near the school, and they came up with practical solutions, e.g. arrange carpooling if distance is too large, use bicycles or switched to walk if possible. This short observation elicits pupils' abilities to understand real data and find the solution to common problems near their areas. The key results from the observation are discussed in the next section.

\section{RESULTS}

The collected data analyzed through number of steps, i.e. categorized the data using coding process, filter the teachers response on each category, interrogate the resulted data corresponding to different categories and finally draw the conclusions. For analyzing the pupils observation, we closely examine the observation to understand the ways pupils work together and discuss the task corresponding to open data visualization.

According to our survey results, teachers are generally highly positive to the concept of including real data-sets in teaching as part of different subjects. They also point out that it will make it relatively easy to relate their subjects to real life and capture pupils' interest. Teaching pupils how to integrate various data-sets from the city's open data and produce practical conclusions allow them to develop, build and establish higher level learning outcomes in their studies. It will also help them to raise the critical questions and make conclusions based on the data available about their local environment. Overall, the interviews also illustrate what competencies pupils already have and which skills, need to be acquired in order to successfully introduce open data in teaching. When we asked one of the teachers about introducing open data in his class, he answered that

"Everything can catch the kids' attention if it is related to their everyday life, and if teachers also think it is fun, then everything is ready to go. You just need to relate what is exciting in the pupils' real world". (Teacher 1, October 23, 2018, 09:42 a.m.)

In relation to introducing visualizations and sensors technology, another teacher answered as

"Pupils can easily accept when it comes to introducing a new tool or technology. They are always excited to work with different and new tools. We just need to learn how to use and grasp these tools". (Teacher 2, October 23, 2018, 15:42 p.m.)

The following are the main key points based on the survey results with school teachers:

\section{Existing skills and competencies}

- 4-6th grade pupils are familiar with small data collections, data arrangements, simple graphical data representations, i.e. curves, columns, and pie charts typically in mathematics.

- In 7th and upper grades the above mentioned topics are taught at an advanced level. Pupils will work with analysis of diagrams and findings. They used these concepts in mathematics along with social sciences and food science subjects.

- Commonly pupils work with tables and charts in papers and hand-ins.

- Pupils in 5-7 grade are familiar with Google Maps and the teachers expect that they would be able to solve simple tasks using user-friendly visualizations software. They are already familiar with Excel, GeoGebra, and similar tools.

- Teachers often use real-life examples for pupils, e.g. in statistics where they can observe the class shoe sizes or hair colors.

- Pupils often collect data outside the school environment, e.g. to measure the height of a tower in a park or counting how many cars pass a road.

\section{Open Data impact}

- Bringing open data into the schools, as parts of different subject will develop the pupils' interest and engagement in learning assignments.

- It will become easy for teachers and pupils to relate real facts of their areas and their city, as part of different subjects.

- Open data can help to improve public awareness among pupils, e.g. pupils will be able to understand how they can help to improve the environment or save energy and contribute to a sustainable use of resources. 
- Open data could support teaching activities in developing pupils' skills to ask questions about different facts related to their subjects as well as their city and local areas.

- Collecting data about their local areas will help pupils to understand the different problems in their area.

- Teachers suggested data-sets about population, traffic, pollution, gender, age and similar as interesting examples for pupils.

- Data collection using sensors will gives pupils a handon experience about how data is generated and how they can use such data for solving a problem.

- Using visualization tools to present open data in schools will create new opportunities for school children to come up with new ideas of understanding their near world and society's problems.

\section{Challenges}

- Teachers have very limited knowledge about open data and visualization tools.

- Most of the open source visualization tools are in English, it is important to explain some of the frequently used terms in pupils' native language.

- Teachers and pupils are not familiar with data cleaning and preparing concepts.

- Teachers and pupils will need smaller and specific open data-sets instead of larger sets in order to relate their subjects to local conditions, e.g. populations, pollution levels or traffic within their local areas.

These key points from the teacher's interviews will help us to analyze teacher's perspective and challenges for open data literacy at schools. Teachers believe that engaging pupils in data exploration will give them a new way to look at e.g. mathematical problem solving and engaging those pupils who do not have interest in traditional approaches. The experiment with pupils shows that active investigation within their local areas using open data, will help build civic awareness among pupils. The interviews also explored the potential of technology to enable out-of-class data collection and new approaches for data learning at schools.

\section{CONCLUSION}

In this research paper, we have presented a study of Copenhagen open data, identified educational open data themes corresponding to educational domains and its potential impact on school pupils in the development of their local areas. We interviewed Danish public school teachers and concluded that instead of assuming open data exploration only for adults, we should introduce these concepts to the next generation of learners. By supporting data literacy at schools, we can empower young pupils to become data experts. Open data literate youth will be able to understand which types of data they need for solving a problem in their daily life, and the use of the latest technology for visualization will enable them to explore the city's open data in greater detail and to present it in an understandable way. In order to face the above mentioned challenges, teacher training programs or workshops where these new concepts are introduced to them can be helpful. This study will contribute as the first step towards open data literacy at Danish schools and pupils engagements in understanding different challenges of their own local areas.

\section{REFERENCES}

[1] Javiera Atenas, Leo Havemann, and Ernesto Priego. 2015. Open Data as Open Educational Resources: Towards transversal skills and global citizenship. Open Praxis 7, 4 (Nov. 2015), 377-389.

[2] Jeppe Bundsgaard and Thomas Illum Hansen. 2016. Blik på undervisning: Rapport om observationsstudier af undervisning gennemført $i$ demonstrationsskoleforsøgene. Technical Report.

[3] Michael Parmisano Canares, Dave Marcial, and Marijoe Narca. 2016. Enhancing citizen engagement with open government data. The fournal of Community Informatics 12, 2 (June 2016).

[4] Chiara Certomà, Mark Dyer, Lorena Pocatilu, and Francesco Rizzi. 2017. Citizen Empowerment and Innovation in the Data-Rich City. Springer, London.

[5] Paul Cobb, Jere Confrey, Andrea DiSessa, Richard Lehrer, and Leona Schauble. 2003. Design experiments in educational research. Educational researcher 32, 1 (Jan. 2003), 9-13. https://doi.org/10.3102/ 0013189X032001009

[6] Gennaro Cordasco et al. 2017. Engaging citizens with a social platform for open data. In Proceedings of the 18th Annual International Conference on Digital Government Research. ACM, New York, NY, USA, 242-249. https://doi.org/10.1145/3085228.3085302

[7] Tim Davies, RM Sharif, and JM Alonso. 2015. Open data barometer global report.

[8] Haiwei Dong, Gobindbir Singh, Aarti Attri, and Abdulmotaleb El Saddik. 2017. Open data-set of seven Canadian cities. IEEE Access 5 (Dec. 2017), 529-543. https://doi.org/10.1109/ACCESS.2016.2645658

[9] Lida Ghahremanlou, Abdel-Rahman H Tawil, Paul Kearney, Hossein Nevisi, Xia Zhao, and Ali Abdallah. 2018. A Survey of Open Data Platforms in Six UK Smart City Initiatives. Comput. f. (July 2018). https://doi.org/10.1093/comjnl/bxy081

[10] Xiping Hu, Terry HS Chu, Henry CB Chan, and Victor CM Leung. 2013. Vita: A crowdsensing-oriented mobile cyber-physical system. IEEE Transactions on Emerging Topics in Computing 1, 1 (June 2013), 148-165.

[11] Marijn Janssen, Yannis Charalabidis, and Anneke Zuiderwijk. 2012. Benefits, adoption barriers and myths of open data and open government. Information systems management 29, 4 (Oct. 2012), 258-268.

[12] Mohammad Saeid Mahdavinejad, Mohammadreza Rezvan, Mohammadamin Barekatain, Peyman Adibi, Payam Barnaghi, and Amit P Sheth. 2018. Machine learning for Internet of Things data analysis: A survey. Digital Communications and Networks 4, 3 (Aug. 2018), 161-175. https://doi.org/10.1016/j.dcan.2017.10.002

[13] Bernard Marr. 2016. Big data in practice: how 45 successful companies used big data analytics to deliver extraordinary results. John Wiley \& Sons.

[14] Cherlton Millette and Patrick Hosein. 2016. A consumer focused open data platform. In Proc. International Conference on Big Data and Smart 
City (ICBDSC) 2016. IEEE, 1-6. https://doi.org/10.1109/ICBDSC.2016. 7460350

[15] Jennifer C Molloy. 2011. The open knowledge foundation: open data means better science. PLoS biology 9, 12 (Dec. 2011), e1001195. https: //doi.org/10.1371/journal.pbio.1001195

[16] United Nations. 2014. World urbanization prospects: The 2014 revision, highlights. department of economic and social affairs.

[17] Charith Perera, Chi Harold Liu, and Srimal Jayawardena. 2015. The emerging internet of things marketplace from an industrial perspective: A survey. IEEE Transactions on Emerging Topics in Computing 3, 4 (Dec. 2015), 585-598. https://doi.org/10.1109/TETC.2015.2390034

[18] Charith Perera, Arkady Zaslavsky, Peter Christen, and Dimitrios Georgakopoulos. 2014. Sensing as a service model for smart cities supported by internet of things. Transactions on Emerging Telecommunications
Technologies 25, 1 (Sept. 2014), 81-93. https://doi.org/10.1002/ett.2704 [19] Oleg Petrov, Joel Gurin, Laura Manley, et al. 2015. Open data for sustainable development.

[20] Alexander Schroll and Andreas Mild. 2011. Open innovation modes and the role of internal R\&D: An empirical study on open innovation adoption in Europe. European fournal of Innovation Management 14, 4 (2011), 475-495. https://doi.org/10.1108/14601061111174925

[21] MF Slot, R Hansen, and J Bremholm. 2016. Elevopgaver og elevproduktion i det 21. århundrede-en kvantitativ og kvalitativ analyse af elevproduktion i matematik, dansk og naturfag.

[22] Ester Van Laar, Alexander JAM van Deursen, Jan AGM van Dijk, and Jos de Haan. 2017. The relation between 21st-century skills and digital skills: A systematic literature review. Computers in human behavior 72 (July 2017), 577-588. https://doi.org/10.1016/j.chb.2017.03.010 